\title{
Needs Assessment of the Residents at the Suez Canal University Hospital Regarding Continuing Professional Development
}

\author{
Doaa Kamal', Nahla Hassan ${ }^{1 *}$,Mohamed Hany ${ }^{2}$, Wagdy Talaat ${ }^{3}$ \\ Departments of ${ }^{1}$ Medical Education, ${ }^{2}$ Family Medicine and, ${ }^{3}$ Pathology, Faculty of Medicine, Suez Canal \\ University, Egypt
}

\begin{abstract}
Background: Continuing Professional Development (CPD) is a continuing learning process that complements formal undergraduate and postgraduate education and training. In order to keep the doctors' pace with changing information and the increased demand from the public for accountability and quality service delivery there is a need for well-planned CPD activities that contribute to further improving standards and meet the identified learning needs. Aim: To assess the needs of the residents working at the Suez Canal University Hospital regarding Continuing Professional Development (CPD). Methods: The study is a descriptive cross-sectional study that included 113 residents affiliated to Suez Canal University Teaching Hospital. A self-administered anonymous questionnaire was distributed to residents to assess their needs concerning CPD. Data was presented in the form of mean, percentage and standard deviation. T-Test was used for comparing means between different specialties and year of residency. The questionnaire was validated through expert opinion. Results: The results of the study showed that for most the resident, there is an importance of introducing different and structured CPD activities after graduation based on their needs, as they were not satisfied with the currently used activities of CPD (reading, lectures, scientific conferences, internet, theses, and patient contact). Among the suggested activities of CPD, clinical training, educational courses and workshops were ranked by the residents as highly useful of achieving CPD objectives, while portfolios and electronic learning were rated as the least useful. Also, most of the resident showed the need for CPD in some areas not directly related to their specialty such as language, administrative skills and leadership skills. Conclusion: the study concluded that there is a real need to introduce a welldesigned Program system of CPD for the resident physicians working at Suez Canal University Hospital taking in consideration the proper selection of the activities as well as the fields of training.
\end{abstract}

Key Words: Continuing Professional Development, resident, needs, activities

\section{Introduction}

Continuing Professional Development (CPD) is a continuing learning process that complements formal undergraduate and postgraduate education and training. CPD requires doctors to maintain and improve their standards across all areas of their practice which include professional roles that doctors currently perform and those that they plan to perform. In addition, CPD should encourage and support specific

*Correspondent Author: nahlah_med@yahoo.com 
changes in practice and career development. It has a role to play in helping doctors to keep up to date when they are not practicing ${ }^{(1)}$. The term Continuing Professions Development stands as a professional imperative of every doctor, and at the same time, it is also a prerequisite for enhancing the quality of health care. CPD differs in principle from the preceding two formal phases of medical education: basic medical education and systematic postgraduate medical training. Whereas the latter two are conducted according to specified rules and regulations, CPD mainly implies self-directed and practice-based learning activities rather than supervised training. In addition to promoting personal professional development, CPD aims to maintain and develop competencies (knowledge, skills and attitudes) of the individual doctor which are essential for meeting the changing needs of patients and the health care delivery system, responding to the new challenges from the scientific development in medicine, and meeting the evolving requirements of licensing bodies and society ${ }^{(2)}$. The term Continuing Medical Education (CME) has been replaced by Continuing Professional Development (CPD), which reflects both the wider context in which this phase of medical education takes place, and signifies that the responsibility to conduct CPD rests with the profession and the individual doctor(3). To deliver the highest quality of patient care, the content of CPD must be directed towards enhancing roles and competencies (both clinical skills and theoretical knowledge), and organization of work (team building and leadership), communication, medical ethics, teaching, research and administration ${ }^{(4,5)}$. The Professional Development Plan (PDP) is central to the CPD process. This allows individuals to direct their own learning schedule and is firmly based in adult learning theory ${ }^{5}$. The personal professional devel- opment plan is a written document that a certified planner creates and saves for his or her personal reference. It is a tool that the planner can use to focus, evaluate and prioritize professional development activities ${ }^{(6)}$. Elements of personal professional development plan may include description or listing of professional aspirations and goals, description or listing of professional interests and activities, history of previously completed professional development activities in order to keep information all in one place, a timeline for several years' worth of future activities or interests, brochures, e-mails, or web links of specific potential professional development activities that may fit the interests and goals of the plan. Including enough materials may expand the plan into a folder or portfolio type of product(7). In addition, effective CPD must be seen as a process rather than an educational event; it can take any form ranging from the traditional and formal to the highly innovative and informal. In CPD, the method of teaching and learning is not the most important variable. More emphasis should be given to the nature and management of the CPD process, summarized as a process of planning, doing and reviewing effect. Planning and performing CPD should be seen as relevant to the needs and interests of the individual, the service, the clinical team and the institution, be it hospital, university or provincial authority, needs assessment is therefore, in most cases, an integral component of successful CPD ${ }^{(8)}$. The six-step approach to reflecting on the individual's CPD may be useful for planning the professional development: Step 1- contextual analysis; Step 2- needs and goals analysis; Step 3individual development plan; Step 4- professional development log; Step 5- professional development record; Step 6- reflection on practice and impact analysis ${ }^{(8)}$. Many hospitals and academic organiza- 
tions offer "rounds", where learners are invited to hear about a given topic in their area of interest. While these are also usually lecture based, there is generally opportunity for the learner to discuss cases or management among colleagues. Learners may also choose to learn through reading journals. The journals may be those to which they subscribe and are specialtyspecific, alternatively, many journals are distributed free of charge to physicians who find themselves on a mailing list of some sort. These journals are generally not peer-reviewed and are of general interest, rather than specialty specific ${ }^{(9)}$. Whether the need identified is specific or general, the learning activities must be planned to be appropriate, and there must be a balance between general and specific CPD. The method of learning is less important than its relevance to the need, and could vary in different circumstances from reading, attending a lecture or a course, a peer-group meeting or a visit to an institution ${ }^{(10)}$. Challenges that may face CPD for residents may include that the strategic healthcare workforce education and planning is not related to service needs. Also, there is not much known of the effectiveness of appraisal for identifying training needs, and how well these are subsequently addressed. Limited coordination among different healthcare education providers and stakeholders can also be one of the challenges that may face CPD. Other challenges include: lack of proper standards for CPD to assure quality of education and courses offered, the accreditation of CPD courses (e.g. conferences, short courses) is not yet established, lack of career advancement and CPD opportunities and commissioning CPD opportunities following appraisal are subject to resource constraints ${ }^{(11)}$. This study was conducted with the aim of assessing the needs of the residents working at the Suez Canal University Hospital regarding CPD and recommending remedial measures of the challenges facing the residents regarding CPD.

\section{Methods}

i. Selection and Description of Participants: This study is a cross- sectional descriptive study that was conducted at Suez Canal University Hospital. The Study population comprised resident working at Suez Canal University Hospital during the time of the study (June-October, 2011). A comprehensive sample was taken and included 113 residents representing all the different specialities in the hospital. ii. Technical Information: The data collection was performed using a self-administered anonymous questionnaire was designed to assess the needs of the residents regarding CPD. The questionnaire included different headlines such as: The importance of CPD after graduation, the already used and available activities of CPD, the best and most useful activities of CPD, the frequency of being engaged in such activities, the need of CPD in some suggested areas not directly related to the residents' specialty and the challenges and barriers facing the residents' regarding CPD. Content validity of the questionnaire was assessed through the subject area experts' review. A meeting was conducted with subject area experts who commented on the content of the questionnaire through adding further needed items or removing useless items.

\section{Statistical Analysis}

Once the completed questionnaires were returned, they were entered onto an Excel Spreadsheet. Data was presented in the form of means, percentages and standard deviations. Tables and graphs were used when appropriate. Data was analyzed using the Statistical Package for the social sciences (SPSS 
version 16). T-Test was used for comparing means between different specialties and year of residency. Chi square will be used to test difference of categorical data. P-values less than 0.05 were considered significant.

\section{Results}

The distribution of the resident according to the year of residency was as follows: $34.50 \%$ of them were in their first year of residency, another $34.50 \%$ were in their second year and 31\% were in their third year of residency. All clinical departments were represented in the study sample, with the largest number ( 13 residents: $11.5 \%)$ from the anaesthesia department and the smallest number (2 residents: $1.80 \%)$ from the urosurgery department. According to the residents doctors' point of view, the majority (70 residents: $61.9 \%$ ) currently use all the mentioned activities in the study questionnaire (reading, lectures, scientific conferences, internet, theses, and patient contact) for CPD. Only few ( 2 residents: $1.8 \%$ ) of them stated that they use theses as one of the activities. Table 1 shows that the majority of the residents were not satisfied with the currently used activities of CPD (52.2\%) while $42.5 \%$ of them were satisfied to some extent and only $5.3 \%$ were completely satisfied with the currently used activities. There were no statistically significant relations between the resident' satisfaction with the already used CPD activities and their specialty or the year of residency $(p=$ 0.76). The clinical training was chosen as most preferred method for CPD among the study group (24.8\%), while portfolio was the least preferred method, (44.2\%) (Table 2).

Table 1: Frequency distribution of study population according to satisfaction with the currently used CPD activities

\begin{tabular}{|c|cc|}
\hline Satisfied with available CPD activities & N & Percent \\
\hline Yes & 6 & $5.3 \%$ \\
To some extent & 48 & $42.5 \%$ \\
No & 59 & $52.2 \%$ \\
Total & 113 & $100 \%$ \\
\hline
\end{tabular}

Regarding the preferred frequency of being engaged in different CPD activities, $68.1 \%$ of the resident preferred participating in monthly workshops, $51.3 \%$ of them preferred participating monthly in conferences, $62.8 \%$ of them preferred to participate monthly in courses and $54.9 \%$ of them preferred to participate monthly in clinical training activities. $63.7 \%$ of the residents preferred the weekly participation in small group discussions, $44.2 \%$ of them also preferred participating weekly in audits and $37.2 \%$ of them preferred to use elearning on weekly basis. The daily use of portfolio and the daily reading were preferred by the residents (43.4\%, and $61.1 \%$ respectively). Most the studied resident were in need for CPD in language, leadership skills administrative skills, communication skills, presentation skills, infection control, especially research methodology (73.5) (Table 3). Concerning the challenges facing the resident regarding CPD, most the resident (43.4\%) stated that lack of support and guidance from their supervisors, lack of appropriate activities, lack of awareness about CPD importance, absence of motivation all are obstacles facing them with high percentage of them chose lack of time as a major obstacle (41.60\%) (Figure 1). 
Table 2: Frequency distribution of study population according to the ranking of some CPD activities from the residents' point of view $(n=113)$

\begin{tabular}{|l|c|c|c|c|c|c|c|c|c|}
\hline \multirow{3}{*}{$\begin{array}{c}\text { CPD activi- } \\
\text { ties }\end{array}$} & \multicolumn{10}{|c|}{ CPD activites Rank } \\
\cline { 2 - 10 } & $\begin{array}{c}1^{\text {st }} \\
\text { No. }\end{array}$ & $\begin{array}{c}2^{\text {nd }} \\
\text { No. }\end{array}$ & $\begin{array}{c}3^{\text {rd }} \\
\text { No. }\end{array}$ & $\begin{array}{c}4^{\text {th }} \\
\text { No. }\end{array}$ & $\begin{array}{c}5^{\text {th }} \\
\text { No. }\end{array}$ & $\begin{array}{c}6^{\text {th }} \\
\text { No. }\end{array}$ & $\begin{array}{c}7^{\text {th }} \\
\text { No. } \\
\%\end{array}$ & $\begin{array}{c}8^{\text {th }} \\
\text { No. } \\
\%\end{array}$ & $\begin{array}{c}9^{\text {th }} \\
\text { No. } \\
\%\end{array}$ \\
\hline Clinical & 28 & 19 & 15 & 17 & 13 & 6 & 7 & 4 & 4 \\
training & $24.8 \%$ & $16.8 \%$ & $13.3 \%$ & $15 \%$ & $11.5 \%$ & $5.3 \%$ & $6.2 \%$ & $3.5 \%$ & $3.5 \%$ \\
\hline Reading & 21 & 7 & 12 & 19 & 9 & 11 & 14 & 9 & 11 \\
& $18.6 \%$ & $6.2 \%$ & $10.6 \%$ & $16.8 \%$ & $8.0 \%$ & $9.7 \%$ & $12.4 \%$ & $8.0 \%$ & $9.7 \%$ \\
\hline Courses & 16 & 18 & 21 & 16 & 11 & 13 & 8 & 9 & 1 \\
& $14.2 \%$ & $15.9 \%$ & $18.6 \%$ & $14.2 \%$ & $9.7 \%$ & $11.5 \%$ & $7.1 \%$ & $8.0 \%$ & $0.9 \%$ \\
\hline Workshops & 16 & 15 & 18 & 12 & 15 & 14 & 10 & 8 & 5 \\
& $14.2 \%$ & $13.3 \%$ & $15.9 \%$ & $10.6 \%$ & $13.3 \%$ & $12.4 \%$ & $8.8 \%$ & $7.1 \%$ & $4.4 \%$ \\
\hline Small group & 14 & 16 & 17 & 10 & 12 & 17 & 19 & 3 & 5 \\
discussions & $12.4 \%$ & $14.2 \%$ & $15 \%$ & $8.8 \%$ & $10.6 \%$ & $15 \%$ & $16.8 \%$ & $2.7 \%$ & $4.4 \%$ \\
\hline Confer- & 8 & 15 & 14 & 19 & 14 & 15 & 14 & 11 & 3 \\
ences & $7.1 \%$ & $13.3 \%$ & $12.4 \%$ & $16.8 \%$ & $12.4 \%$ & $13.3 \%$ & $12.4 \%$ & $9.7 \%$ & $2.7 \%$ \\
\hline Audit & 8 & 9 & 7 & 6 & 18 & 12 & 12 & 29 & 12 \\
& $7.1 \%$ & $8.0 \%$ & $6.2 \%$ & $5.3 \%$ & $15.9 \%$ & $10.6 \%$ & $10.6 \%$ & $25.7 \%$ & $10.6 \%$ \\
\hline E-learning & 1 & 10 & 7 & 11 & 14 & 13 & 15 & 20 & 22 \\
& $0.9 \%$ & $8.8 \%$ & $6.2 \%$ & $9.7 \%$ & $12.4 \%$ & $11.5 \%$ & $13.3 \%$ & $17.7 \%$ & $19.5 \%$ \\
\hline Portfolio & 2 & 4 & 3 & 2 & 7 & 12 & 13 & 20 & 50 \\
& $1.8 \%$ & $3.5 \%$ & $2.7 \%$ & $1.8 \%$ & $6.2 \%$ & $10.6 \%$ & $11.5 \%$ & $17.7 \%$ & $44.2 \%$ \\
\hline
\end{tabular}

\section{Discussion}

The primary steps for introducing and applying a CPD system in an organization include assessing and analyzing the needs for CPD. As Suez Canal University Hospital is not applying a structured program for CPD, this descriptive study was conducted to be a first step in increasing the awareness of residents about CPD, recognizing their needs for CPD and also in recognizing the challenges that may be facing them during their professional development. The overall responses of the residents were in favor of the importance of CPD after graduation. This finding agreed with Siddiqui ${ }^{(12)}$ study in which needs assessment of about 500 physicians in Pakistan was performed and it showed that the majority of those doctors agreed that CPD was important. In the current study, readings, lectures, scientific conferences, internet, theses, and dealing with the patients were identified by the residents in varying percentages as the currently used activities of CPD. This finding is also congruent with Schostak's(13) study of the effectiveness of CPD in which he emphasized that reading journals and conference attendance were the most common CPD activities undertaken by his study population. A study held by Waters ${ }^{(14)}$ showed similar results, it assessed how UK GP trainers developed themselves as teachers. The CPD activity that was used by the smallest number of studied population in the current study was the research theses (1.8\%) and this finding goes with the findings of Siddiqui( ${ }^{(12)}$ who emphasized that CPD activities that were undertaken by the smallest number of doctors in his study were writing and research. 
Table 3: Frequency distribution of study population according to the need for CPD in areas not directly related to their specialty $(n=113)$

\begin{tabular}{|l|c|c|c|}
\hline \multirow{2}{*}{ Skills } & \multicolumn{3}{|c|}{ CPD Need } \\
\cline { 2 - 4 } & $\begin{array}{c}\text { Yes } \\
\text { No. (\%) }\end{array}$ & $\begin{array}{c}\text { To some extent } \\
\text { No. }(\%)\end{array}$ & $\begin{array}{c}\text { No } \\
\text { No. }(\%)\end{array}$ \\
\hline Language & $65(57.5 \%)$ & $40(35.4 \%)$ & $8(7.1 \%)$ \\
\hline Leadership & $62(54.9 \%)$ & $46(40.7 \%)$ & $5(4.4 \%)$ \\
\hline Administrative & $60(53.1 \%)$ & $38(33.6 \%)$ & $15(13.3 \%)$ \\
\hline Infection Control and Prevention & $66(58.4 \%)$ & $42(37.2 \%)$ & $5(4.4 \%)$ \\
\hline Quality Management & $62(54.2 \%)$ & $44(38.9 \%)$ & $7(6.2 \%)$ \\
\hline Communication & $55(48.7 \%)$ & $48(42.2 \%)$ & $10(8.8 \%)$ \\
\hline Team Work & $67(59.3 \%)$ & $38(33.6 \%)$ & $8(7.1 \%)$ \\
\hline Presentation & $64(56.6 \%)$ & $47(41.6 \%)$ & $2(1.8 \%)$ \\
\hline Learning and Teaching & $55(48.7 \%)$ & $51(45.1 \%)$ & $7(6.2 \%)$ \\
\hline Research Methodology & $83(73.5 \%)$ & $27(23.9 \%)$ & $3(2.7 \%)$ \\
\hline
\end{tabular}

The results of our study are inconsistent with the results of the WHO-Egyptian Medical Syndicate Project(21) ${ }^{(2)}$ Establishing a National CPD Strategy for Health Professionals in Egypt which emphasized that the majority of the medical practitioners participated in that project were involved in clinical training programs and workshops as part of their CPD, this inconsistency may be attributed to the decreased availability of such activities for the residents in our context. Most the residents were not satisfied with the currently used activities of CPD (52.2\%), and this may be due to the limited number of choices in addition to the lack of a structured CPD program. In the current study there was no statistically significant relation between the residents' satisfaction with the currently used CPD activities and their specialty or year of residency; this could be due to the lack of a structured CPD program for the residents at the site of the study. Also, the used activities were not based on their needs. The current study revealed that $24.8 \%$ of the residents preferred clinical training as the best tool of CPD and $14.2 \%$ of them preferred cours- es as one of the CPD activities. This was consistent with Van den Berg(15) who stated in his assessment study of the preferences of general practitioners of the CPD activities that most of his study population selected journals, courses and lectures as the most favored activities of CPD and also with Lee ${ }^{(16)}$ who reported in his study of the radiographers' perceptions that most of his study population stated that training programs and workshops are highly beneficial to their personal and professional development. The current study also revealed that $14.2 \%$ selected workshops as beneficial tool of CPD and this finding is consistent with Water ${ }^{(14)}$ who declared that high percentage of his study population were in favor of using workshops as a tool of CPD. In contrast to Van den Berg's(15) study; portfolio was relatively the least favoured tool of CPD by the residents in the current study while in his study the least favoured tool was reading. This could be explained by the cultural differences and the decreased awareness of the residents at the SCUH about the portfolio and its importance as a tool of CPD as well 


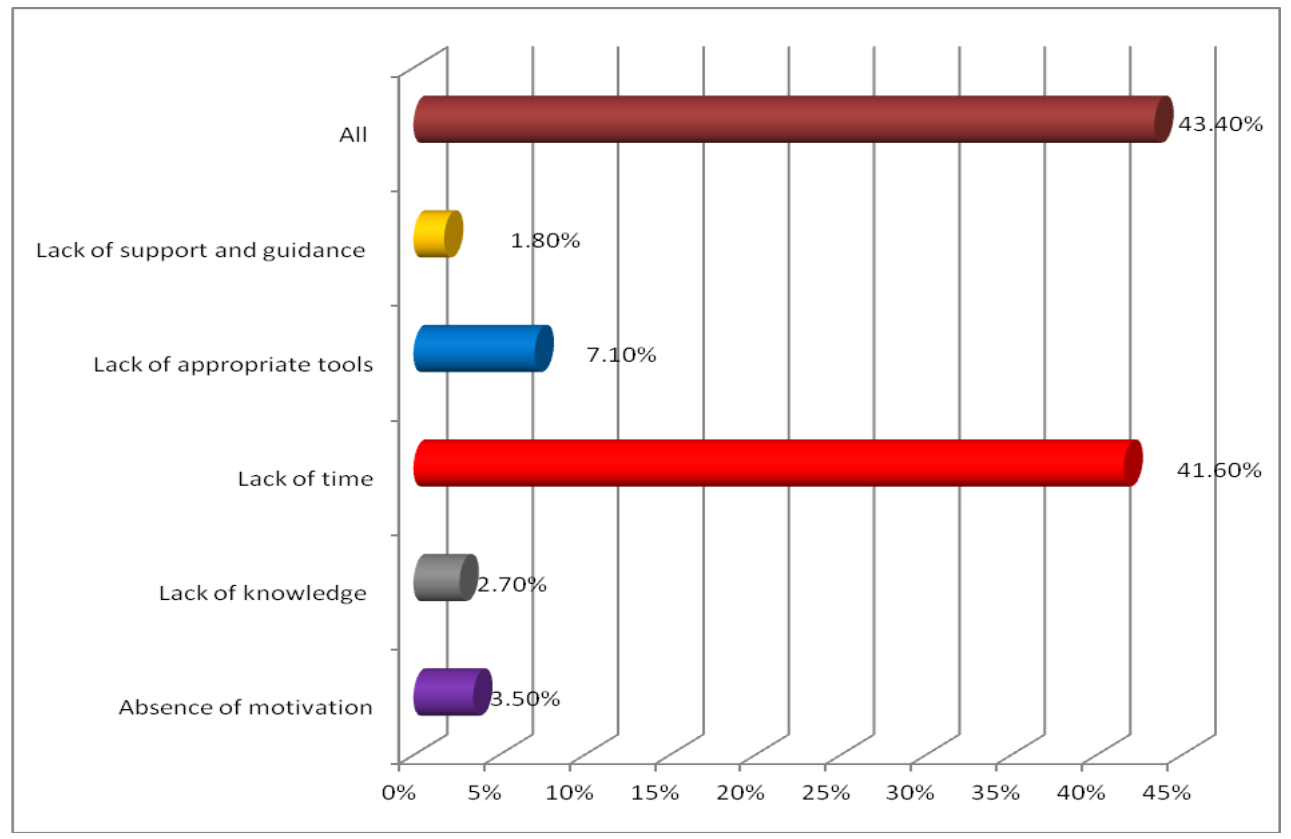

Figure 1: Frequency distribution of the study population according the challenges facing them regarding $\operatorname{CPD}(n=113)$

as the differences in learning style between the two study populations. Another activity of CPD with relatively least preference by the residents in our study was the e-learning and this result is matching with that of the WHO-Egyptian Medical Syndicate Project in which the participated medical practitioners preferred all face to face CPD activities rather than distance learning activities(21). The current study revealed that the majority of the residents agreed that there are some areas not directly related to their specialty in which they need CPD such as research methodology, communication skills and the leadership skills; this finding was inconsistent with Brigley's(17) study of Wales (UK) hospital doctors' views of their CPD and its relationship to learning in the organization which stated that the majority of his studied population in his survey displayed a preference for traditional approaches to CPD. They chose areas of CPD that they felt had practical relevance: updating of clinical knowledge and procedures and, to a lesser extent, topics such as time management, communication skills and IT; he stated also that doctors in his study continue to assume that CPD is simply a matter of updating clinical knowledge and skills and that this can be relied on to produce changes in clinical practice. The inconsistency between our study and Brigley ${ }^{(17)}$ may be attributed to the innovative approaches used in undergraduate education at the faculty of medicine, Suez Canal University such as problem solving approach which increases and develops the medical students' competences and encourages self and continuing learning. The majority of the residents in our study defined a number obstacles that may pre vent them from being engaged in the CPD activities including lack of support and guidance through the CPD process, lack of appropriate activities, shortage of time, lack of proper understanding about the importance of CPD and also the absence- 
of motivation regarding CPD, these findings were congruent with those of the WHO-Egyptian Medical Syndicate Project ${ }^{(21)}$ in which lack of sufficient political support from the relevant authorities for attending and participating in CPD activities as well as the absence of controlling laws and regulating bylaws of the already available CPD activities and activities were considered the major challenges facing most of the medical practitioners participated in that project. Lack of time was a common barrier to CPD experienced by the participants in Lee' $s^{(16)}$ study followed by lack of access to CPD activities, lack of funding and lack of support and commitments from the department and theses findings are also consistent with our results. The challenges and barriers defined by our studied population were also in congruence with those of the majority of the physiotherapists working as lone practitioners in amputee rehabilitation in United Kingdom (UK) representing the studied sample of Cole's ${ }^{(18)}$ study which include inadequate access to opportunities and to specialist staff, lack of direct observation of the practice, lack of formal recognition of the necessity for CPD at an organizational level and lack of time for CPD. The findings in the current study are consistent with Butterworth ${ }^{(20)}$ who declared that the majority of the doctors working in rural Nepal experienced barriers to undertaking CPD such as the lack of actual CPD resources, lack of time and the need for someone to co-ordinate a CPD program. In contrast to Waters( ${ }^{(13)}$ study which declared that the studied populations' beliefs regarding the importance and value of educational CPD is one of the important difficulties to CPD, only small number of our studied population selected lack of importance and significance of CPD as the one of the barriers to CPD. This inconsistency may be due to the need of the studied population in the former study for a more applied system of CPD to their clinical life and not only educational system which may be time consuming and representing an overload on them without paying attention to other areas in which the residents need more development.

\section{Conclusion}

The study concluded that it is important for the residents at the SCUH to acquire more knowledge about the CPD and its principles and that there is a need to develop a structured program of CPD to be applied and used by the residents. It showed that the residents themselves were interested in being involved in such a system. The study strongly recommends disseminating the results to the relevant authorities utilizing them as basis for strategic planning of the CPD system.

\section{References}

1. General Medical Council. Continuing Professional Development, GMC Publications, London, 2004.

2. Basic Medical Education WFME Standards Quality Improvement. WFME office, University of Copenhagen, Denmark, 2003.

3. Accreditation Council for Continuing Medical Education. Standards. ACCME, USA, 2002.

4. European Union of Medical Specialists. Charter on Continuing Medical Education in the European Union. UEMS, 1994.

5. Grant J, Chambers E, Jackson G. The Good CPD Guide. Reed Healthcare Publishing, Sutton, 1999.

6. European Union of Medical Specialists. Basal Declaration. UEMS Policy on Continuing Professional Development. UEMS, 2001.

7. Personal Professional Development plan.

https://www.planning.org/static I_pdf/cm/profdevplan.pdf 
8. Batmangelich S, Adamowski S. Maintenance of Certification in the United States : A Progress Report. J Contin Educ Health Prof 2004 ; 24:134-8.

9. College of Physicians and Surgeons of Ontario, Personal Communication, 2004.

10. Schostaka J, Davisb M, Hansonc J, Schostakd J, Browne T, Jenkinsh N, The Effectiveness of Continuing Professional Development, Designs and Patents Act, 2010.

11. Davis N, Davis D, Bloch R. Continuing medical education: AMEE Education Guide No 35. Med Teach 2008; 30 (7): 652-66.

12. Siddiqui ZS, Secombe MJ, Peterson R. Continuous professional development-development of a framework for medical doctors in Pakistan. J Pak Med Assoc 2003;53:290293.

13. Schostak J, Davis M, Hanson J, et al. Effectiveness of Continuing Professional Development' project: A summary of findings. Med Teach 2010;32 (7):586-92.

14. Waters $M$, Wall D. Educational CPD: how UK GP trainers develop themselves as teachers. Med Teach 2007;29 (6):160-9.

15. Van den Berg L, De Villiers MR. CPD: the learning preferences of general practitioners. SA Fam Pract 2003;45(3):10-12.

16. Lee S, Reed W, Poulos A. Continuing Professional Development: the perceptions of Radiographers' in New South Wales, The Radiographer 57, 33-39. [online] Retrieved October 20, 2011 from http://www.minniscomms.com. au/radiographer/articles.php?article id $=608$.

17. Brigley S, Johnson C, Bird J, Young H. Hospital doctors' views of their CPD and its relationship to learning in the organization; Med Teach 2006;28(4):379-81.

18. Cole MJ, Morris J, Scammell A. Challenges of CPD for physiotherapists working as lone practitioners in amputee rehabilitation. Prosthet Orthot Int. 2008 ;32(3):264-75.

19. Lloyd-Williams $M$, et al. Continuing Professional Development (CPD) in palliative medicine: A survey; Med Teach 2006;28(2): 171-4.

20. Butterworth K, Hayes B,Zimmerma M. Needs Assessment for Continuing Medical Education amongst doctors working in Rural Nepal; South East Asian J Med Educ 2010;4(1):34-42.

21. Egyptian Medical Syndicate. Establishing a National CPD Strategy for Health Professionals in Egypt; A WHO-Egyptian Medical Syndicate Project (final report), 2010.

\section{Acknowledgement:}

The authors would like to thank the residents in Suez Canal University Hospital who participated in this study. 
